\title{
Impact of Anions on the Partition Constant, Self-Diffusion, Thermal Stability, and Toxicity of Dicationic Ionic Liquids
}

\author{
Clarissa P. Frizzo, ${ }^{* \dagger}{ }^{\dagger}$ Caroline R. Bender, ${ }^{\dagger}$ Paulo R. S. Salbego, ${ }^{\dagger}{ }^{\dagger}$ Carla A. A. Farias, ${ }^{\dagger}$
}

Thayanara C. da Silva, ${ }^{\ddagger}$ Sílvio T. Stefanello, ${ }^{\ddagger}$ Tássia L. da Silveira, ${ }^{\ddagger}$ Félix A. A. Soares, ${ }^{\ddagger}$ Marcos A. Villetti, and Marcos A. P. Martins ${ }^{\dagger}$

${ }^{\dagger}$ Núcleo de Química de Heterociclos (NUQUIMHE), Department of Chemistry, ${ }^{\ddagger}$ Department of Biochemistry and Molecular Biology, and ${ }^{\S}$ Laboratório de Espectroscopia e Polímeros (LEPOL), Department of Physics, Federal University of Santa Maria (UFSM), CEP 97105-900 Santa Maria, RS, Brazil

\section{Supporting Information}

ABSTRACT: Partition constants $\left(K_{\mathrm{D}}^{\circ}\right)$, molecular dynamics $\left(T_{1}, T_{2}\right.$, and DOSY measurements), thermal stability, and toxicity of dicationic ionic liquids (ILs) were determined. The dicationic ILs derived from 1,n-bis(3-methylimidazolim-1yl)octane, $\left[\mathrm{BisOct}(\mathrm{MIM})_{2}\right][2 \mathrm{X}]$ (in which $\mathrm{X}=\mathrm{Cl}, \mathrm{Br}, \mathrm{NO}_{3}$, $\mathrm{SCN}, \mathrm{BF}_{4}$, and $\mathrm{NTf}_{2}$ ), were evaluated to verify the influence of anion structure on the IL properties. A monocationic IL $[\operatorname{Oct}(\mathrm{MIM})][\mathrm{Br}]$ was also monitored for comparison. In

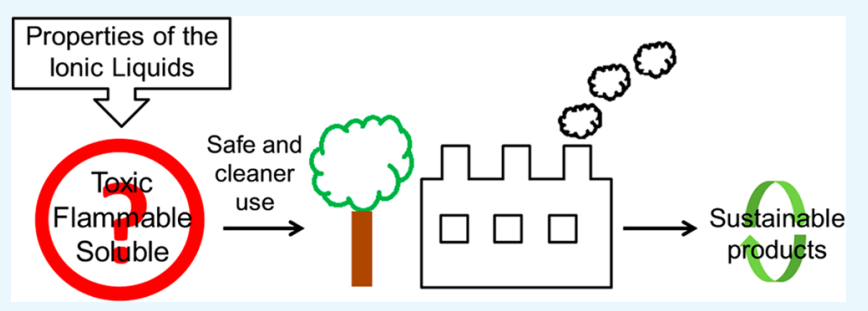
general, the solubility of the ILs followed the anion free energy of hydration $\left(\Delta G_{\text {hyd }}^{\circ}\right)$. The thermokinetic and thermodynamic functions of activation of the ILs were determined via thermogravimetric data, and it was observed that polyatomic anions influence the decomposition mechanism of these IL structures. Furthermore, $[\mathrm{Oct}(\mathrm{MIM})][\mathrm{Br}]$ had a decomposition rate greater than that of the dicationic analogue, and the thermodynamic parameters of activation data corroborate these results. Finally, the dicationic ILs did not indicate toxic effects $\left(\mathrm{LD}_{50}>40 \mathrm{mM}\right)$.

\section{INTRODUCTION}

Ionic liquids (ILs) have been an option for a wide range of applications. This is due to their unusual and adjustable properties, which manifest in accordance with changes in their structures. Low vapor pressure and chemical and thermal stability make them very good solvents for many chemical reactions and separations. ${ }^{1-11}$ Furthermore, a wide electrochemical window and the high conductivity of ILs enable their use as electrolytes in solar cells and batteries. ${ }^{12}$

Imidazolium-based ILs are the most investigated IL class. Dicationic ILs have been used as solvents, ${ }^{13}$ as surfactants, ${ }^{14,15}$ lubricants, ${ }^{16}$ and for nanoparticle coatings. ${ }^{16}$ However, obtaining ILs that have enhanced physicochemical properties as well as low toxicity is very challenging. The lack of information regarding IL properties is a major barrier to the utilization of these compounds.

The solubility and the diffusion rate parameters for ILs can limit the reaction conversions and charge transport, thus making these properties particularly interesting for synthetic and electrochemical applications. The higher thermal stability provides several engineering advantages, e.g., thermal energy storage and heat-transfer fluids. ${ }^{17}$ Finally, toxicity is a key parameter to be determined due to environmental contamination, or when ILs are designed for biomedical applications. ${ }^{18-20}$

Changing the structure of the cations and anions leads to ILs with physical, chemical, and biological properties designed for specific purposes. ${ }^{21}$ It is known that the anions of ILs have some influence on the overall toxicity of these structures. In general, the higher the hydrophobicity of anions, the more toxic and less biodegradable they are. ${ }^{18}$ The partition constant $\left(K_{\mathrm{D}}^{\circ}\right)$ is related to the likelihood of a compound accumulating in an organism because the water-saturated 1-octanol is a model of the cell in living organisms. ${ }^{22}$ This is important for determining the solubility in water and the possible effect of ILs on aquatic environments.

To contribute to the research on dicationic imidazoliumbased ILs, the goal of this investigation was to obtain a greater understanding of the influence that anions have on the ILs' physicochemical properties. Partition constant, molecular dynamics (self-diffusion coefficient and relaxation times), toxicity, and thermal stability were evaluated. Dicationic ILs with different anions were chosen to evaluate different physicochemical and biological properties as a function of the anions' characteristics. A monocationic IL was used to compare the data. The ILs selected are shown in Figure 1.

\section{RESULTS AND DISCUSSION}

2.1. Determination of the Partition Constants of the ILs. The solubility properties of the dicationic ILs are predicted

Received: November 28, 2017

Accepted: December 29, 2017

Published: January 22, 2018 


\begin{tabular}{|c|c|c|}
\hline Cations & \multicolumn{2}{|c|}{ Anions } \\
\hline $\mathrm{H}_{3} \mathrm{C}-\mathrm{N}+\mathrm{N}-\left(\mathrm{CH}_{2}\right)_{8}-\mathrm{N}+\mathrm{N}-\mathrm{CH}_{3}$ & 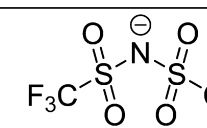 & $\begin{array}{l}\mathrm{S}=\mathrm{C}=\mathrm{N}^{\ominus} \\
{[\mathrm{SCN}]^{-}}\end{array}$ \\
\hline$\left[\mathrm{BisOct}(\mathrm{MIM})_{2}\right]^{2+}$ & & $\mathrm{Cl}^{\ominus}$ \\
\hline 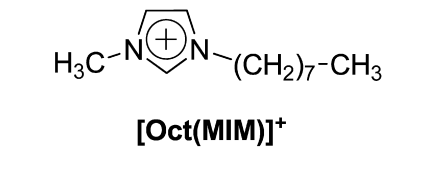 & 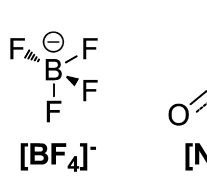 & $\begin{array}{c}{[\mathrm{Cl}]^{-}} \\
\ominus \\
\mathrm{Br} \\
{[\mathrm{Br}]^{-}}\end{array}$ \\
\hline
\end{tabular}

Figure 1. Structure of the cations and anions of the ILs used.

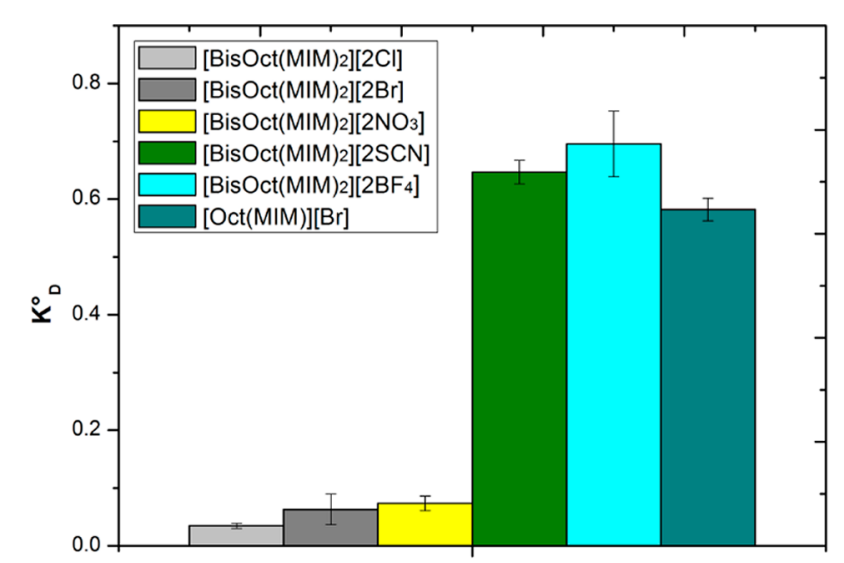

(a)

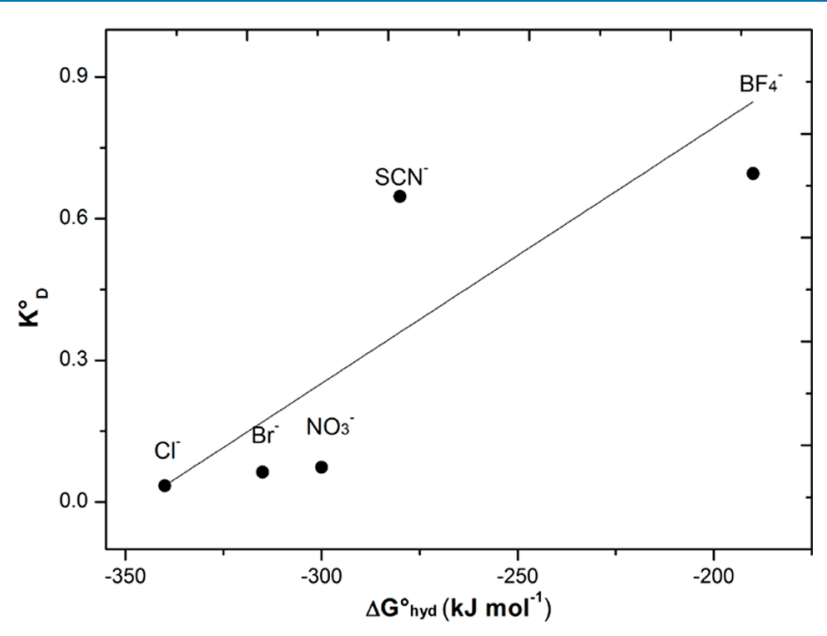

(b)

Figure 2. (a) Comparison of $K_{\mathrm{D}}^{\circ}$ values for the ILs and (b) $K_{\mathrm{D}}^{\circ}$ as a function of $\Delta G^{\circ}$ hyd for the anions of the dicationic ILs.

from the determination of the partition constant $\left(K_{\mathrm{D}}^{\circ}\right)$, which is calculated via eq $1^{23}$ and enables the calculation of the amount of IL remaining in water in a 1-octanol/water system.

$$
K_{\mathrm{D}}^{\circ}=\frac{[\mathrm{IL}]_{\text {octanol }}}{[\mathrm{IL}]_{\text {water }}}
$$

In eq 1 , the partition constant $\left(K_{\mathrm{D}}^{\circ}\right)$ is the ratio between the concentration of IL at equilibrium in both phases, i.e., in 1octanol $\left([\mathrm{IL}]_{\text {octanol }}\right)$ and in water $\left([\mathrm{IL}]_{\text {water }}\right)$. The $K_{\mathrm{D}}^{\circ}$ value is essential for understanding the tendency of an IL to bioaccumulate by passing through biological membranes. This is possible because the dielectric properties of 1-octanol are similar to a lipid phase. ${ }^{24}$

For this study, a calibration curve of absorbance as a function of the concentration of the solution is constructed for each IL in water. The absorbance measurements are obtained using spectroscopy of molecular absorption in the UV-vis region. The graph for absorbance versus wavelength $(\lambda)$ and the calibration curves of $\left[\mathrm{BisOct}(\mathrm{MIM})_{2}\right][2 \mathrm{X}]$ (in which $\mathrm{X}=\mathrm{Br}$, $\mathrm{Cl}, \mathrm{NO}_{3}, \mathrm{SCN}$, and $\left.\mathrm{BF}_{4}\right)$ and $[\mathrm{Oct}(\mathrm{MIM})][\mathrm{Br}]$ are shown in the Supporting Information (SI).

In accordance with the methodology, after $24 \mathrm{~h}$, the water content is separated from 1-octanol and the absorbance is measured. The concentration of IL remaining in the water is determined from the equation of the predetermined calibration curve. The $[\mathrm{IL}]_{\text {octanol }}$ concentration was calculated from the equation $100-[\mathrm{IL}]_{\text {water }}$ (in which 100 is the initial IL concentration, in $\mathrm{mM}$ ), and then the $K_{\mathrm{D}}^{\circ}$ values are determined (Figure 2a). From the $K_{D}^{\circ}$ data, a solubility order for the dicationic ILs in water, in accordance with the anions, was established: $\left[\mathrm{BF}_{4}\right]^{-}<[\mathrm{SCN}]^{-}<\left[\mathrm{NO}_{3}\right]^{-}<[\mathrm{Br}]^{-}<[\mathrm{Cl}]^{-}$. These results are related to the anion free energy of hydration $\left(\Delta G^{\circ}{ }_{\text {hyd }}\right)$ taken from Marcus, ${ }^{25}$ see Figure $2 \mathrm{~b}$.

The progression of $\Delta G^{\circ}$ hyd to less negative values makes the anions increasingly hydrophobic. This parameter may be related to the solubility of ILs that have different anions in their structures. Figure $2 \mathrm{~b}$ shows that the $K_{\mathrm{D}}^{\circ}$ values of dicationic ILs tend to increase with an increase in $\Delta G^{\circ}$ hyd (less negative values). Therefore, more positive the $\Delta G_{\text {hyd }}^{\circ}$ the smaller the hydration degree of the ILs and the higher the $K_{\mathrm{D}}^{\circ}$. Thus, it can be seen that the dicationic IL [BisOct(MIM) $)_{2}$ $[2 \mathrm{Br}]$ is more soluble in water than its monocationic analogue $[\mathrm{Oct}(\mathrm{MIM})][\mathrm{Br}]$. The greater solubility in water shown by $\left[\mathrm{BisOct}(\mathrm{MIM})_{2}\right][2 \mathrm{Br}]$ may be related to the fact that it has one more cationic head than $[\operatorname{Oct}(\mathrm{MIM})][\mathrm{Br}]$, which enables better interaction of the structure with the aqueous phase. $K_{\mathrm{D}}^{\circ}$ values for several monocationic ILs with different anions and alkyl chain lengths have already been established in the literature. ${ }^{22,23,26}$ To the best of our knowledge, $K_{\mathrm{D}}^{\circ}$ values have not yet been measured for dicationic ILs. For monocationic ILs with the $\left[\mathrm{NTf}_{2}\right]^{-}$anion, the $K_{\mathrm{D}}^{\circ}$ value increases as the alkyl chain length on the cation increases. ${ }^{22}$ This behavior is attributed to the van der Waals interactions between the alkyl chain of the IL and the 1-octanol molecules. Furthermore, it has been observed that $K_{\mathrm{D}}^{\circ}$ is dependent on the IL concentration; in general, for the same IL cation [But(MIM) $]^{+}$, the $K_{\mathrm{D}}^{\circ}$ values follow the trend of anion hydrophilicity. ${ }^{22}$ The same is observed for the dicationic ILs evaluated in this study. 


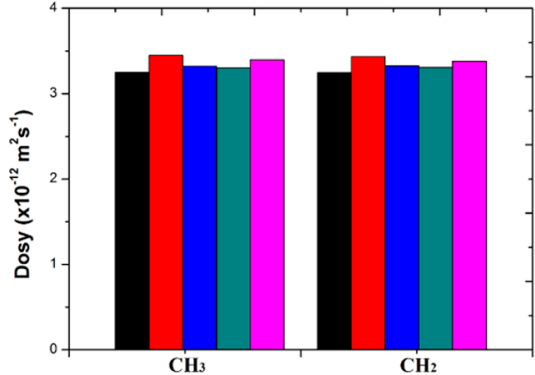

(a)

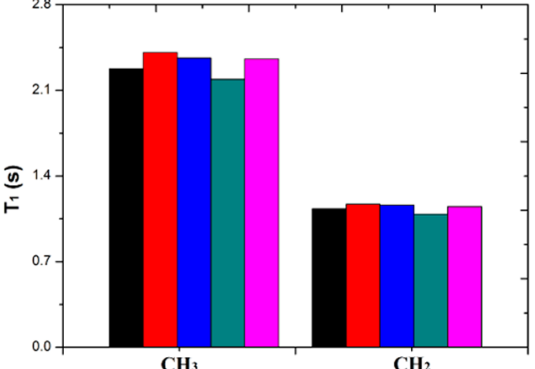

$\mathrm{CH}_{3}$

(b)

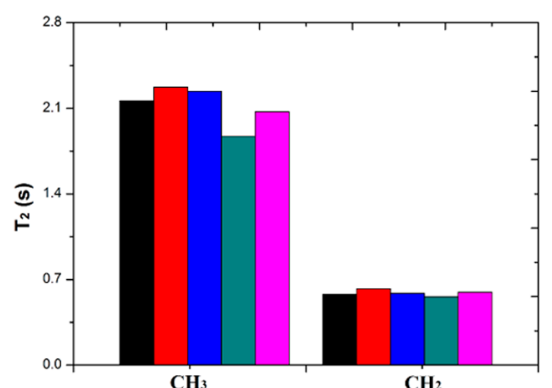

(c)

Figure 3. (a) Self-diffusion coefficient $(D)$, (b) longitudinal relaxation time $\left(T_{1}\right)$, and (c) transverse relaxation time $\left(T_{2}\right)$ for $\left[\mathrm{BisOct}(\mathrm{MIM})_{2}\right][2 \mathrm{X}]$, in which $\mathrm{X}=\mathrm{Cl}$ (black), $\mathrm{Br}$ (red), $\mathrm{NO}_{3}$ (blue), $\mathrm{SCN}$ (cyan), or $\mathrm{BF}_{4}$ (magenta), in $\mathrm{D}_{2} \mathrm{O}(50 \mathrm{mM})$ at $25^{\circ} \mathrm{C}$.

The $K_{\mathrm{D}}^{\circ}$ values for the monocationic IL analogues of the dicationic ILs addressed in this study (in which $\mathrm{X}=\mathrm{Cl}, \mathrm{NO}_{3}$, $\mathrm{SCN}$, and $\mathrm{BF}_{4}$ ) are not found in the literature; for this reason, it is not possible to establish a comparison. Due to the very low solubility of $\left[\mathrm{BisOct}(\mathrm{MIM})_{2}\right]\left[2 \mathrm{Ntf}_{2}\right]$ in water, $K_{\mathrm{D}}^{\circ}$ of this IL cannot be evaluated. For the same reason, the molecular dynamics and toxicity data of this IL are also not determined.

\subsection{Self-Diffusion Coefficient and Relaxation Times of}

ILs. The self-diffusion coefficients $(D)$ are determined via the DOSY experiments. The $T_{1}$ and $T_{2}$ measurements are acquired to understand the relaxation process as a function of the selfdiffusion of the $\mathrm{IL}$ structures in water. The signals monitored are $\mathrm{CH}_{3}$ and $\mathrm{CH}_{2}$ directly bound to the imidazolium ring of the ILs. The results are shown in Figure 3.

The $D, T_{1}$, and $T_{2}$ values do not indicate a linear relationship with $\Delta G^{\circ}{ }_{\text {hyd }}$, which is an estimation of the hydrophobicity of the structures of the ILs. Figure 3a shows that the $D$ values of the ILs do not indicate significant changes in accordance with the anion used in the structure, the values were between $3.24 \times$ $10^{-12}$ and $3.72 \times 10^{-12} \mathrm{~m}^{2} \mathrm{~s}^{-1}$. Furthermore, considerable changes are not observed in the $D$ values in accordance with the ${ }^{1} \mathrm{H}$ nuclei evaluated ( ${ }^{1} \mathrm{H}$ from $\mathrm{CH}_{2}$ or $\mathrm{CH}_{3}$ dication groups). In general, the $D$ values for the cation and anion of a given IL are similar, and this may be an indication of the presence of a cooperative transport phenomenon in which the cation and anion diffuse as an ion pair. ${ }^{27,28}$ In this study, the IL anions do not have hydrogens in the structure; therefore, only cations signals are evaluated.

The $T_{1}$ values of the dicationic ILs are considerably lower for $\mathrm{CH}_{2}$ of the spacer chain in comparison with the terminal $\mathrm{CH}_{3}$ group, which is expected because the internal $\mathrm{CH}_{2}$ can relax more effectively because of the dipolar relaxation mechanism, ${ }^{29}$ see Figure 3b. However, pronounced differences are not observed in relation to the anion type for the same group evaluated $\left(\mathrm{CH}_{2}\right.$ or $\left.\mathrm{CH}_{3}\right)$. Figure $3 \mathrm{c}$ shows the transverse relaxation time $\left(T_{2}\right)$ for the dicationic ILs. The $T_{2}$ values observed for $\mathrm{CH}_{2}$ are lower than those for $\mathrm{CH}_{3}$, which is consistent with the explanation suggested for $T_{1}$ behavior. Additionally, as expected, the $T_{2}$ values are always lower than the $T_{1}$ values. $^{29}$

The lack of correlation in the data in relation to the anion hydrophobicity is expected. The anions have a secondary role in these experiments because the intermolecular dipole-dipole interactions make a smaller contribution to the relaxation process $^{30}$ than the intramolecular dipole-dipole interactions that occur in the dications. Furthermore, as the IL diffused as an ion pair, the size of the dication in the ILs evaluated could explain the similar $D$ observed because $D$ is dependent on the hydrodynamic radius of the diffusing species in the solution, and the anions do not have major size differences between each other. $^{21,28}$ In a recent study published by our research group, it was observed that the anions $\left(\mathrm{Br}, \mathrm{NO}_{3}, \mathrm{SCN}\right.$, and $\left.\mathrm{BF}_{4}\right)$ of $\left[\right.$ BisOct $\left.(\mathrm{MIM})_{2}\right][2 \mathrm{X}]$ do not influence the hydrodynamic radius of the aggregates in a solution (determined by dynamic light scattering) at different concentrations $(50,300$, and 500 $\mathrm{mM})^{31}$

Even though we have observed that ILs with more hydrophobic anions (e.g., $\mathrm{BF}_{4}^{-}$) tend to form greater and more compact aggregates because $\mathrm{BF}_{4}{ }^{-}$anions interact more effectively with IL cation heads in the solution, ${ }^{32}$ this was not relevant for the $D, T_{1}$, and $T_{2}$ values of [BisOct $\left.(\mathrm{MIM})_{2}\right]\left[2 \mathrm{BF}_{4}\right]$ in relation to other species. Furthermore, the larger the aggregate, the lower the $D$ value because bigger structures tend to diffuse more slowly than the smaller ones.

The $T_{1}, T_{2}$, and $D$ values of $\left[\operatorname{BisOct}(\mathrm{MIM})_{2}\right][2 \mathrm{Br}]$ are compared with those of the monocationic analogue [Oct(MIM) $][\mathrm{Br}]$, see Table $S 3$ in the SI. The $D$ value of $[\operatorname{Oct}(\mathrm{MIM})][\mathrm{Br}]$ is slightly higher $\left(0.5 \times 10^{-12} \mathrm{~m}^{2} \mathrm{~s}^{-1}\right)$ than that of $\left[\mathrm{BisOct}(\mathrm{MIM})_{2}\right][2 \mathrm{Br}]$. The $T_{1}$ and $T_{2}$ values of $[\mathrm{Oct}(\mathrm{MIM})][\mathrm{Br}]$ are nearly double those of $\left[\mathrm{BisOct}(\mathrm{MIM})_{2}\right]$ $[2 \mathrm{Br}]$. This indicates that the presence of an additional cationic head in $\left[\mathrm{BisOct}(\mathrm{MIM})_{2}\right][2 \mathrm{Br}]$ leads to a slower diffusion of the species in water while stimulating a faster relaxation process for dicationic IL than for monocationic analogues.

2.3. Thermal Stability Properties of the ILs. Decomposition kinetics studies are done to determine the influence that the structural parameters of anions have on the thermal degradation process of ILs, and to elucidate which ILs can be used in applications involving high temperatures. The decomposition profile of $\left[\mathrm{BisOct}(\mathrm{MIM})_{2}\right][\mathrm{Br}]$ at the heating rates of $2,3,5,7$, and $10{ }^{\circ} \mathrm{C} \mathrm{min}{ }^{-1}$ is shown in Figure 4 . The decomposition profiles of other ILs are shown in the SI. The thermogravimetric analysis (TGA) curve has only one endothermic peak, without any apparent loss of mass up to $520 \mathrm{~K}$ (there was only one mass loss stage).

From the TGA data, two different methodologies are used to analyze the decomposition kinetics of the ILs: the OzawaWall-Flynn $(\mathrm{O}-\mathrm{W}-\mathrm{F})$ and Friedman methodologies. ${ }^{33}$ Both methods enable the determination of kinetic parameters from the nonisothermal thermogravimetric data at different heating rates. The weight loss variation observed in the TGA analysis is called the mass fraction of conversion $(\alpha)$, which is calculated via eq $2 .^{34}$ 


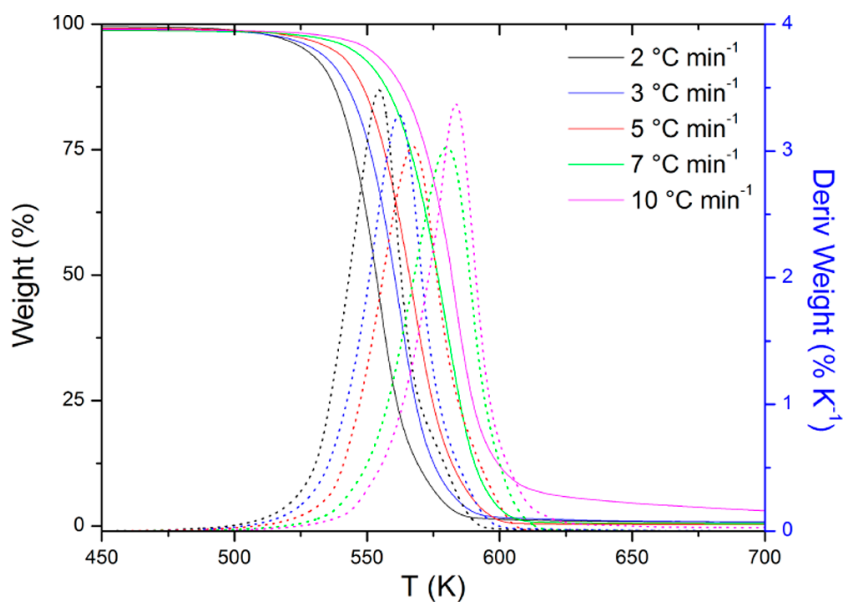

Figure 4. Overlap of TGA thermograms for $\left[\operatorname{BisOct}(\mathrm{MIM})_{2}\right][2 \mathrm{Br}]$ at different heating rates.

$$
\alpha=\frac{m_{0}-m_{\mathrm{f}}}{m_{0}-m_{t}}
$$

In which $m_{0}$ is the initial mass, $m_{\mathrm{f}}$ is the final mass, and $m_{t}$ is the mass at time $t$. The kinetics results from the $\mathrm{O}-\mathrm{W}-\mathrm{F}$ method are obtained via eq 3. A graph showing $\ln (\beta)$ versus $1 / T$ for each value of $\alpha$ is constructed, see Figure $5 a^{34}$

$$
\ln \beta=\ln \left[A \frac{f(\alpha)}{\mathrm{d} \alpha / \mathrm{d} T}\right]-\frac{E_{\mathrm{a}}}{R T}
$$

In eq $3, \beta$ is the heating rate, $A$ is the collision factor representing the total number of collisions between molecules, $E_{\mathrm{a}}$ is the activation energy necessary to break one mole of bonds between the atoms of the molecules, $T$ is the absolute temperature, and $R$ is the constant of ideal gases. The Friedman method enables determination of the kinetic parameters by linear fitting of the $\ln (\beta \mathrm{d} \alpha / \mathrm{d} t)$ curve as a function of $1 / T$ in nonisothermal experiments (eq 4), see Figure $5 b^{34}$ The equation $f(\alpha)=(1-\alpha)$ is considered for both methods in this study.

$$
\ln \left(\beta \frac{\mathrm{d} \alpha}{\mathrm{d} T}\right)=\ln [A f(\alpha)]-\frac{E_{\mathrm{a}}}{R T}
$$

The angular coefficient of the linear fragments in each $\alpha$ of the two different methods (Figure 5) gives the energy activation $\left(E_{\mathrm{a}}\right)$ value of the decomposition process, see Figure 6. From the $E_{\mathrm{a}}$ values, the collision factor $(A)$ can be estimated by applying the Arrhenius equation ${ }^{35}$ (Figure 6).

The $E_{\mathrm{a}}$ and $\ln A$ of $\left[\mathrm{BisOct}(\mathrm{MIM})_{2}\right][2 \mathrm{Br}]$ remain constant for all of the $\alpha$ evaluated. This indicates that as a function of temperature, the decomposition reaction of this IL occurs in a single step with an average activation energy of $145.18 \mathrm{~kJ}$ $\mathrm{mol}^{-1}$, which is determined via the $E_{\mathrm{a}}$ obtained from the $\mathrm{O}-\mathrm{F}-$ $\mathrm{W}$ method (Figure 6a). The same tendency is observed via the Friedman method (Figure 6b).

For the $\left[\mathrm{BisOct}(\mathrm{MIM})_{2}\right][2 \mathrm{X}]$ ILs (in which $\mathrm{X}=\mathrm{NTf}_{2}, \mathrm{BF}_{4}$, and $\mathrm{NO}_{3}$ ), the $E_{\mathrm{a}}$ and $\ln A$ values increase with the increase in $\alpha$ from 0.1 to 0.9 . In these cases, side reactions occur during the decomposition process (multiple steps). These reactions involve competitive reaction pathways with different reaction rates, which are dependent on the temperature and heating rates. The IL $\left[\mathrm{BisOct}(\mathrm{MIM})_{2}\right][2 \mathrm{SCN}]$ has a distinct behavior in which the $E_{\mathrm{a}}$ and $\ln A$ decrease as $\alpha$ increases, see Section 3 in the SI.

In the IL based on the imidazolium ring, it is proposed that the major component of thermal degradation is the neutralization of the imidazolium ring through a second-order nucleophilic substitution $\left(S_{N} 2\right)$ that occurs with the loss of the IL's alkyl chain. ${ }^{17}$ The decomposition of [BisOct $\left.(\mathrm{MIM})_{2}\right][2 \mathrm{Br}]$ in a single step could be related to this $S_{N} 2$ dealkylation reaction in the dication of the IL. On the other hand, in the $\left[\operatorname{BisOct}(\mathrm{MIM})_{2}\right][2 \mathrm{X}]$ ILs (in which $\mathrm{X}=\mathrm{NTf}_{2}, \mathrm{BF}_{4}, \mathrm{NO}_{3}$, and $\mathrm{SCN}$ ), multiple reactions can occur simultaneously, which leads to modifications in the $E_{\mathrm{a}}$ and $\ln A$ as the $\alpha$ changes. This behavior may be related to the additional bond breaks in the anions of these ILs. For the IL $[\mathrm{Bu}(\mathrm{MIM})]\left[\mathrm{NTf}_{2}\right]$, the $\mathrm{NTf}_{2}$ decomposition has already been predicted via the density functional theory (DFT) calculations. ${ }^{36}$ In this case, the IL decomposition occurs via an exothermic reaction with the release of sulfur dioxide $\left(\mathrm{SO}_{2}\right)$. ILs containing non-nucleophilic anions (e.g., the bis(trifluoromethylsulfonyl)imide anion)

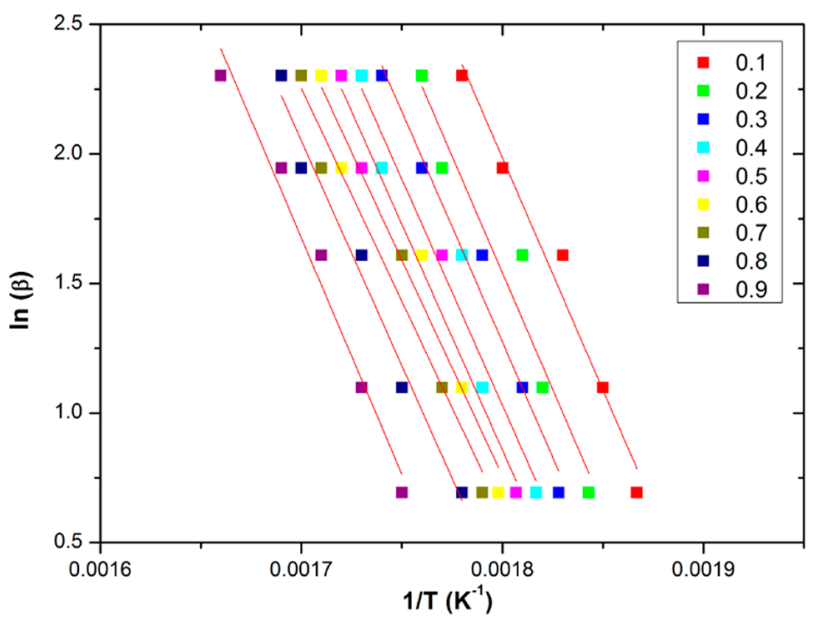

(a)

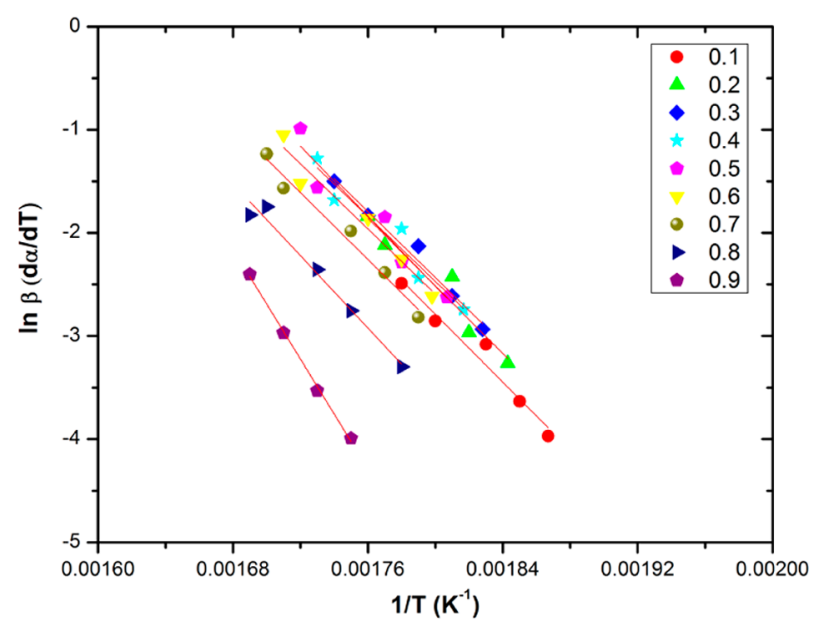

(b)

Figure 5. Curves that show (a) $\ln \beta$ vs $1 / T$ and (b) $\ln \beta(\mathrm{d} \alpha / \mathrm{d} T)$ vs $1 / T$ for $\left[\operatorname{BisOct}(\mathrm{MIM})_{2}\right][2 \mathrm{Br}]$. 


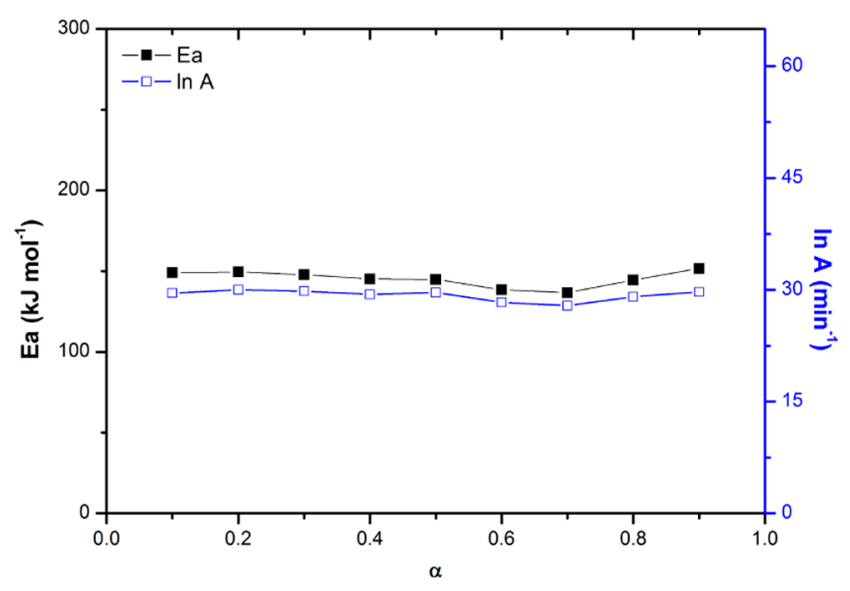

(a)

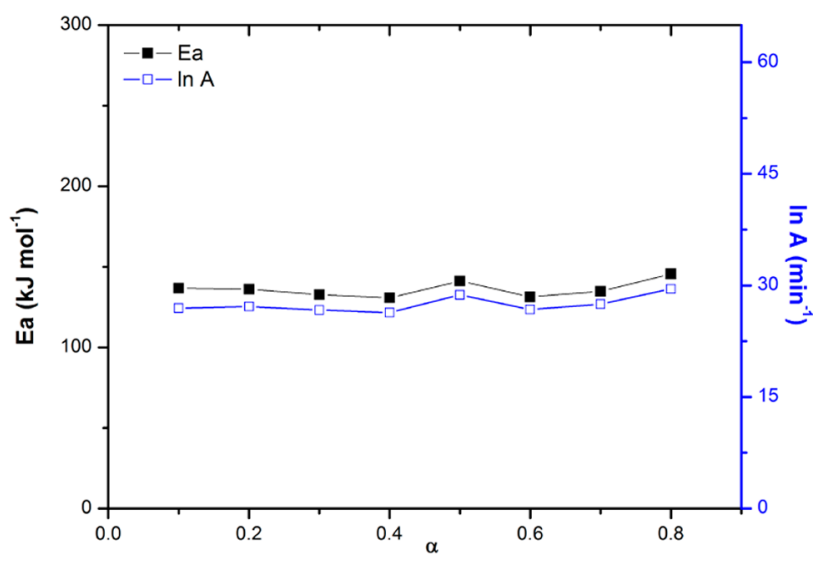

(b)

Figure 6. Curves that show $E_{\mathrm{a}}$ vs $\alpha$ vs $\ln A$ for $\left[\mathrm{BisOct}(\mathrm{MIM})_{2}\right][2 \mathrm{Br}]$ obtained by the application of the (a) $\mathrm{O}-\mathrm{F}-\mathrm{W}$ and (b) Friedman methods to the TGA experimental data.

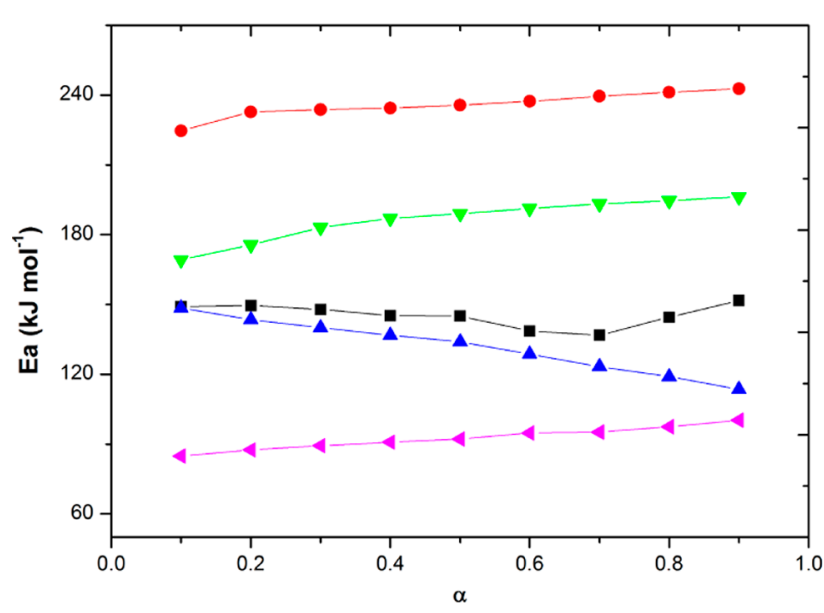

(a)

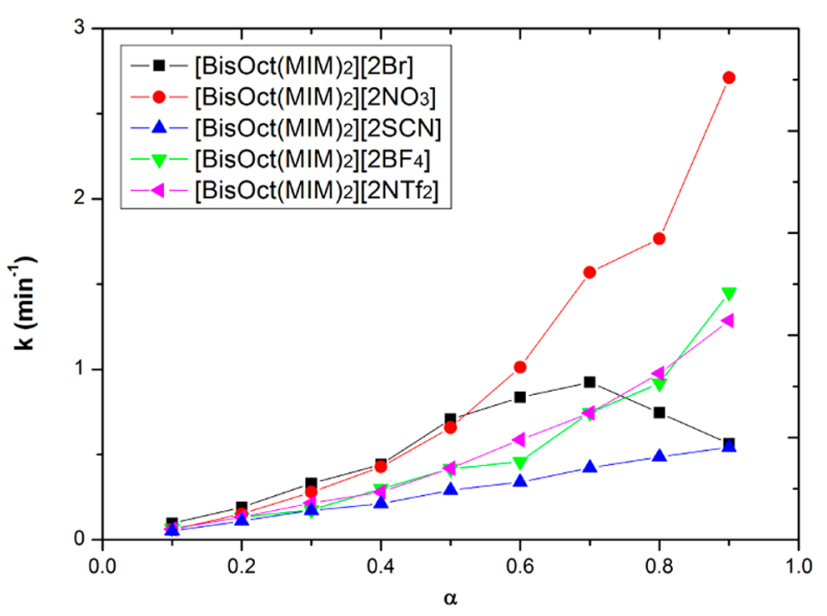

(b)

Figure 7. Relationship between (a) $E_{\mathrm{a}}$ vs $\alpha$ and (b) $k$ vs $\alpha$ for $\left[\mathrm{BisOct}(\mathrm{MIM})_{2}\right][2 \mathrm{X}]$, in which $\mathrm{X}=(\boldsymbol{\square}) \mathrm{Br},(\boldsymbol{\bullet}) \mathrm{NO}_{3},(\boldsymbol{\Delta}) \mathrm{SCN}_{1}(\boldsymbol{\nabla}) \mathrm{BF}_{4}$, and $(<$ $\mathrm{NTf}_{2}$, ascertained via the $\mathrm{O}-\mathrm{F}-\mathrm{W}$ method.

Table 1. Comparison of Thermokinetic and Thermodynamic Parameters of Activation (at $25{ }^{\circ} \mathrm{C}$ ) to Determine the Largest Thermal Degradation Component of the ILs Obtained by the O-F-W Method

\begin{tabular}{|c|c|c|c|c|c|c|}
\hline IL & $E_{\mathrm{a}}\left(\mathrm{kJ} \mathrm{mol}^{-1}\right)$ & $\ln A\left(\min ^{-1}\right)$ & $\Delta G^{\ddagger}\left(\mathrm{kJ} \mathrm{mol}{ }^{-1}\right)$ & $\Delta H^{\ddagger}\left(\mathrm{kJ} \mathrm{mol}{ }^{-1}\right)$ & $\Delta S^{\ddagger}\left(\mathrm{kJ} \mathrm{mol}^{-1} \mathrm{~K}^{-1}\right)$ & $-T \Delta S^{\ddagger}\left(\mathrm{kJ} \mathrm{mol}{ }^{-1}\right)$ \\
\hline \multirow[t]{2}{*}[\mathrm{BisOct}(\mathrm{MIM})_{2}]{$[2 \mathrm{Br}]$} & $149.07^{a}$ & $29.57^{a}$ & $158.94^{a}$ & $146.60^{a}$ & $-0.0414^{a}$ & $12.34^{a}$ \\
\hline & $144.95^{b}$ & $29.64^{b}$ & $154.65^{b}$ & $142.47^{b}$ & $-0.0408^{b}$ & $12.18^{b}$ \\
\hline \multirow[t]{2}{*}[\operatorname{BisOct}(\mathrm{MIM})_{2}]{$\left[2 \mathrm{BF}_{4}\right]$} & $169.16^{a}$ & $26.80^{a}$ & $185.89^{a}$ & $166.68^{a}$ & $-0.0644^{a}$ & $19.21^{a}$ \\
\hline & $189.06^{b}$ & $30.51^{b}$ & $186.46^{b}$ & $186.58^{b}$ & $-0.0336^{b}$ & $10.02^{b}$ \\
\hline \multirow[t]{2}{*}[\mathrm{BisOct}(\mathrm{MIM})_{2}]{$\left[2 \mathrm{NO}_{3}\right]$} & $224.70^{a}$ & $43.93^{a}$ & $198.96^{a}$ & $222.22^{a}$ & $0.0778^{a}$ & $-23.25^{a}$ \\
\hline & $235.61^{b}$ & $46.62^{b}$ & $203.20^{b}$ & $233.13^{b}$ & $0.1003^{b}$ & $-29.92^{b}$ \\
\hline \multirow[t]{2}{*}[\mathrm{BisOct}(\mathrm{MIM})_{2}]{$\left[2 \mathrm{NTf}_{2}\right]$} & $84.82^{a}$ & $21.11^{a}$ & $115.63^{a}$ & $82.35^{a}$ & $-0.1118^{a}$ & $33.33^{a}$ \\
\hline & $92.20^{b}$ & $23.42^{b}$ & $117.31^{b}$ & $89.72^{b}$ & $-0.0925^{b}$ & $27.60^{b}$ \\
\hline \multirow[t]{2}{*}[\mathrm{BisOct}(\mathrm{MIM})_{2}]{$[2 \mathrm{SCN}]$} & $148.50^{a}$ & $29.39^{a}$ & $158.81^{a}$ & $146.02^{a}$ & $-0.0429^{a}$ & $12.80^{a}$ \\
\hline & $133.95^{b}$ & $25.83^{b}$ & $153.08^{b}$ & $131.47^{b}$ & $-0.0724^{b}$ & $21.61^{b}$ \\
\hline \multirow[t]{2}{*}[\mathrm{Oct}(\mathrm{MIM})]{$[\mathrm{Br}]$} & $138.98^{a}$ & $28.10^{a}$ & $152.49^{a}$ & $136.50^{a}$ & $-0.0536^{a}$ & $15.98^{a}$ \\
\hline & $191.44^{b}$ & $39.39^{b}$ & $176.98^{b}$ & $188.96^{b}$ & $0.402^{b}$ & $-11.98^{b}$ \\
\hline
\end{tabular}




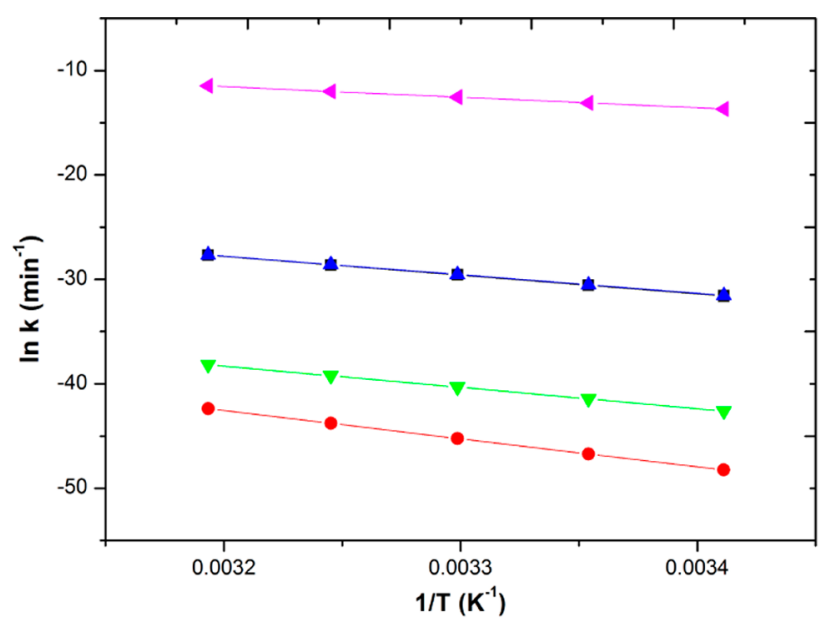

(a)

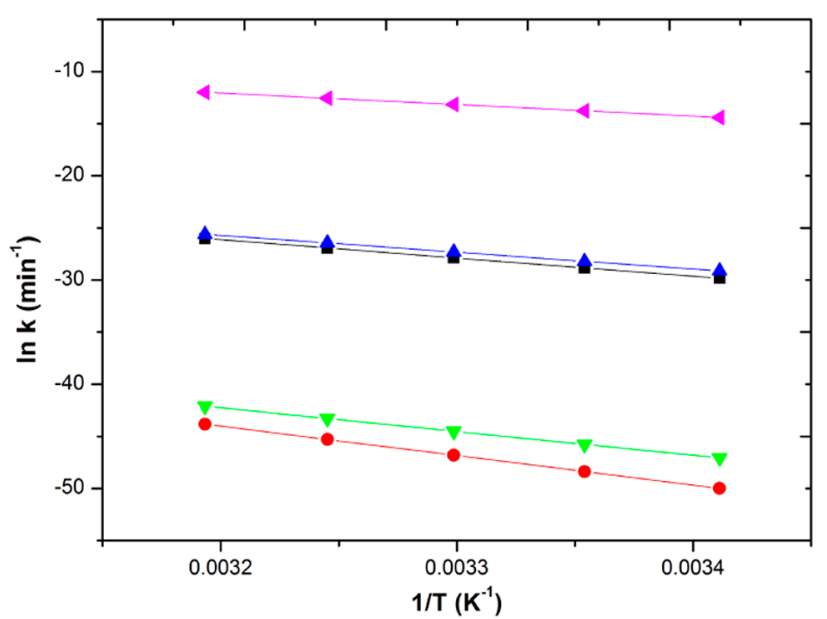

(b)

Figure 8. Relationship between $\ln k$ vs $1 / T$ for (a) $10 \%$ activity loss and (b) $50 \%$ activity loss for [BisOct $\left.(\mathrm{MIM})_{2}\right][2 \mathrm{X}]$, in which $\mathrm{X}=(\boldsymbol{\square}) \mathrm{Br},(\boldsymbol{\bullet})$ $\mathrm{NO}_{3},(\boldsymbol{\Delta}) \mathrm{SCN},(\boldsymbol{\nabla}) \mathrm{BF}_{4}$, and $(\boldsymbol{\Lambda}) \mathrm{NTf}_{2}$, ascertained via the $\mathrm{O}-\mathrm{F}-\mathrm{W}$ method.

cannot decompose via dealkylation or proton transfer, the latter is less likely due to the high energy barrier for the decomposition calculated by DFT. ${ }^{36}$

The $E_{\mathrm{a}}$ values show the energy difference between the reactants and the transition state. The greater the $E_{\mathrm{a}}$ values, the more energy is required for the reactants to reach the transition state of the decomposition reaction. The difference in the profile of $E_{\mathrm{a}}$ as a function of $\alpha$ observed for this IL series shows that the anions of the IL structures promote pronounced changes in the thermal degradation of dicationic ILs (Figure $7 \mathrm{a})$. The profile of the degradation process rate's constant $(k)$ for each IL versus $\alpha$ indicates some differences as $\alpha$ increases (Figure 7b). Initially $(\alpha<0.5)$, the rate constant's decomposition behavior can be attributed to the major thermal degradation component of these ILs, neutralization of the imidazolium ring through an $\mathrm{S}_{\mathrm{N}} 2$ reaction between the anion and carbon directly bound to the imidazolium ring, being the same for $\left[\mathrm{BisOct}(\mathrm{MIM})_{2}\right][2 \mathrm{X}]$ (in which $\mathrm{X}=\mathrm{Br}, \mathrm{BF}_{4}, \mathrm{NO}_{3}$, and SCN). When $\alpha$ is greater than 0.5 , the differences in the degradation process's profile can be related to the energy involved in the groups moving away from the structures of the anions. As previously mentioned, the thermal degradation of $\left[\mathrm{BisOct}(\mathrm{MIM})_{2}\right]\left[2 \mathrm{NTf}_{2}\right]$ is different because the degradation mechanism of this IL initially occurs via the $\mathrm{SO}_{2}$ release.

The kinetic parameters $\left(E_{a}, A\right.$, and $\left.k\right)$ obtained are used to evaluate the thermodynamic parameters of activation for the ILs. The thermodynamic parameters for the thermal decomposition of the ILs are calculated at $25{ }^{\circ} \mathrm{C}$, using $E_{\mathrm{a}}$ and $\ln A$ values in $\alpha$ of 0.1 and 0.5 . The $\alpha$ values of 0.1 and 0.5 correspond to 10 and $50 \%$ of activity loss, respectively. Determination of the kinetic parameters for $10 \%$ of activity loss is important for the pharmaceutical industry because it is generally associated with the shelf life of the compounds, whereas $50 \%$ of the activity loss is associated with the half-life of the compounds. The data for the thermodynamic parameters of activation, including entropy $\left(\Delta S^{\ddagger}\right)$, enthalpy $\left(\Delta H^{\ddagger}\right)$, and Gibbs free energy $\left(\Delta G^{\ddagger}\right)$ of activation, are shown in Table 1 . They were calculated using the following equations. ${ }^{37}$

$$
A \exp \frac{-E_{\mathrm{a}}}{R T}=v \exp \frac{-\Delta G^{\ddagger}}{R T}
$$

$$
\begin{aligned}
& \Delta H^{\ddagger}=E_{\mathrm{a}}-R T \\
& \Delta G^{\ddagger}=\Delta H^{\ddagger}-T \Delta S^{\ddagger}
\end{aligned}
$$

In eqs 5,6 , and $7, v=k_{\mathrm{B}} T / h$ (in which $k_{\mathrm{B}}$ is the Boltzmann constant and $h$ is the Plank constant), $T$ is the temperature in $\mathrm{K}$, and $R$ is the gas constant in $\mathrm{kJ} \mathrm{mol}^{-1}$.

The $\Delta G^{\ddagger}$ is influenced by the $\Delta H^{\ddagger}$ and $\Delta S^{\ddagger}$ of the activated complex formation. The value of the activation enthalpy shows energy differences between the activated complex and the initial IL structure. As expected, the $\Delta G^{\ddagger}$ and $\Delta H^{\ddagger}$ values are positive due to the decomposition of ILs being an endergonic and endothermic process, respectively. These parameters show that the decomposition reactions of the ILs are nonspontaneous and dependent on heating. The larger and more positive the $\Delta H^{\ddagger}$ values, the more energy is necessary to break the covalent bonds of the ILs. The dicationic IL with $\mathrm{NO}_{3}$ anion is the most thermally stable structure, followed by $\mathrm{BF}_{4}, \mathrm{Br}, \mathrm{SCN}$, and $\mathrm{NTf}_{2}$ for all of the $\alpha$ evaluated. In general, the $\Delta H^{\ddagger}$ values follow the same trend as the $\Delta G^{\ddagger}$ data, and they are dependent on several exo- and endothermic decomposition reactions. The relatively low stability of $\left[\mathrm{BisOct}(\mathrm{MIM})_{2}\right]\left[2 \mathrm{NTf}_{2}\right]$ can be attributed to (i) the considerable volatility of imidazolium-based ILs possessing $\mathrm{NTf}_{2}$ counter ions ${ }^{38,39}$ and (ii) the exothermic release of $\mathrm{SO}_{2}$ molecules in the decomposition of the anions. $^{17,36}$ The decomposition kinetics of $[\operatorname{Oct}(\mathrm{MIM})][\mathrm{Br}]$ elucidated through the isothermal TG data is established by Arellano et al. ${ }^{35}$ In this work, the $E_{\mathrm{a}}$ and $\ln A$ values found for the $533-573 \mathrm{~K}$ temperature range are $219.89 \mathrm{~kJ} \mathrm{~mol}^{-1}$ and $48.19 \mathrm{~min}^{-1}$, respectively. However, the thermodynamic parameters of activation $\left(\Delta G^{\ddagger}, \Delta H^{\ddagger}\right.$, and $\left.\Delta S^{\ddagger}\right)$ of the process are not determined. In this present study, in the same temperature range and with $\alpha=0.5$, the $E_{\mathrm{a}}$ and $\ln A$ values for $[\mathrm{Oct}(\mathrm{MIM})][2 \mathrm{Br}]$ obtained via the nonisothermal $\mathrm{O}-\mathrm{F}-$ $\mathrm{W}$ method were $230.27 \mathrm{~kJ} \mathrm{~mol}^{-1}$ and $39.38 \mathrm{~min}^{-1}$, respectively. Considering that different methods are used in this investigation compared to the work of Arellano et al., ${ }^{35}$ the values show a good agreement.

The low activation entropy values indicate that the compounds have a low reactivity, and that the time required to attain the activated complex is long. ${ }^{37}$ Thus, the lower $\Delta S^{\ddagger}$ 
values for these ILs confirm that the decomposition process's activated complex has a higher degree of arrangement. Although the $\Delta S^{\ddagger}$ values of the reactions are negative, due to the activation complex being more organized in relation to the reactants, the $\left[\mathrm{BisOct}(\mathrm{MIM})_{2}\right]\left[2 \mathrm{NO}_{3}\right](\alpha=0.1$ and 0.5$)$ and $[\operatorname{Oct}(\mathrm{MIM})][\mathrm{Br}](\alpha=0.5)$ have small positive entropy values. These results can be attributed to the large $E_{\mathrm{a}}$ and $\ln A$ values obtained via the experimental data. The decomposition process for these structures is dependent on a complex set of reactions occurring at the same time. Thus, the positive $\Delta S^{\ddagger}$ values observed for these structures may be the result of a sum of separated reaction entropies. The mechanism for thermal IL degradation is complex because multiple parameters must be considered. The decomposition mechanisms are subject to multiple simultaneous reactions, autocatalytic effects, and competing reaction pathways with different reaction rates dependent on temperature and the heating rate. ${ }^{17,38}$

Figure 8a,b shows $\ln k$ versus $1 / T$ for IL decomposition in $\alpha$ $=0.1$ and $\alpha=0.5$, respectively. As observed, the first-order reaction kinetics for dicationic IL degradation follows the Arrhenius rate law. The straight lines show the same trend for both 10 and 50\% activity loss. Nevertheless, for 50\% weight loss, the straight lines of $\left[\mathrm{BisOct}(\mathrm{MIM})_{2}\right]\left[2 \mathrm{NO}_{3}\right]$ and $\left[\mathrm{BisOct}(\mathrm{MIM})_{2}\right]\left[2 \mathrm{BF}_{4}\right]$ move closer together. On the other hand, the overlapped straight lines of the dicationic ILs with $\mathrm{Br}^{-}$and $\mathrm{SCN}^{-}$anions for $10 \%$ activity loss separate slightly for $50 \%$ activity loss.

2.4. Toxicity of ILs. The relationship between the chemical structure and cellular toxicity of monocationic imidazoliumbased ILs is well established. ${ }^{40}$ Results show that the cytotoxicity of these ILs is governed by the alkyl chain length, in which the higher toxicity exerted by more hydrophobic ILs (with longer alkyl chains) is associated with an increase in membrane permeability and a change in the physical properties of the lipid bilayer. ${ }^{41}$ The anion also has an important effect on the cytotoxicity of monocationic ILs. The structures with more hydrophobic anions have a higher toxicity than those prepared with more hydrophilic anions. ${ }^{40}$ This feature is related to the stronger interactions with cell membranes and hydrophobic protein domains, which could potentially disrupt essential physiological functions. ${ }^{42}$

On the other hand, the cellular toxicity of dicationic imidazolium-based ILs is poorly understood. Steudte et al. ${ }^{43}$ performed an initial evaluation of the hazard potential of cations in 10 dicationic ILs by measuring toxicity at different levels of biological complexity. The results showed that the toxicity of standard dialkylimidazolium ILs is, in many cases, lower than that for monocationic ILs. The authors found that the short terminal side chains and head groups connected via short alkyl chains are like structural elements, which reduce the toxicity.

Gindri et al. ${ }^{44}$ investigated the anion effect on the toxicity of dicationic imidazolium-based ILs in MC3T3-E1 preosteoblast cells. The authors reported that the dicationic IL toxicity is reduced compared to that for monocationic IL, and they attributed this to the additional cationic head in the dicationic ILs. In the series evaluated, $\left[\mathrm{BisOct}(\mathrm{MIM})_{2}\right][2 \mathrm{Br}]$ is considered to be the IL with the lowest toxicity.

Besides the cellular toxicity of ILs, the biodegradability of ILs has become important due to environmental impacts. ${ }^{40,45,46}$ In terms of their ecological and biological activity, the impact of IL-based processes on the environment is not well established, which could be a limitation to the practical use of the procedures involving ILs.

Caenorhabditis elegans is a free-living soil nematode that is also found in aquatic habitats, thus making it suitable for chemical exposures in aqueous media. ${ }^{47}$ It is considered to be a model organism for toxicological studies due to its wellcharacterized genome, similarity to human biology, ease of maintenance, and short and prolific life cycle. ${ }^{48}$ Thus, it is important to consider the survival of these nematode species as an indicator of the environmental impact and ecological activity of ILs, especially in the initial planning and optimization of ILbased process. There are no studies that report the toxicological effects that dicationic ILs have on nematode species. A study with monocationic imidazolium-based IL show that the aforementioned IL has dose-dependent toxic effects on the survival of $C$. elegans. ${ }^{49}$ In the same study, a median lethal concentration $\left(\mathrm{LC}_{50}\right)$ of $4.71 \mathrm{mM}$ was measured for [Oct$(\mathrm{MIM})][\mathrm{Br}]$ after $24 \mathrm{~h}$ exposure.

Here, we perform an initial investigation of the toxicological effects that the dicationic $\left[\mathrm{BisOct}(\mathrm{MIM})_{2}\right][2 \mathrm{X}]$ ILs (in which $\mathrm{X}=\mathrm{Cl}, \mathrm{Br}, \mathrm{NO}_{3}, \mathrm{SCN}$, and $\mathrm{BF}_{4}$ ) have on the survival of $\mathrm{C}$. elegans. In an initial scanning, the worms in the larval stage (first stage is more sensible) were exposed to different IL concentrations $(0.01,0.1,1.0$, and $10 \mathrm{mM})$ for $1 \mathrm{~h}$. From these data, it is observed that the survival rate of the worms remained above $90 \%$, indicating that these dicationic ILs do not have toxic effects at all of the concentrations evaluated (Figure 9). Furthermore, the toxic anion effect on the survival of $C$.

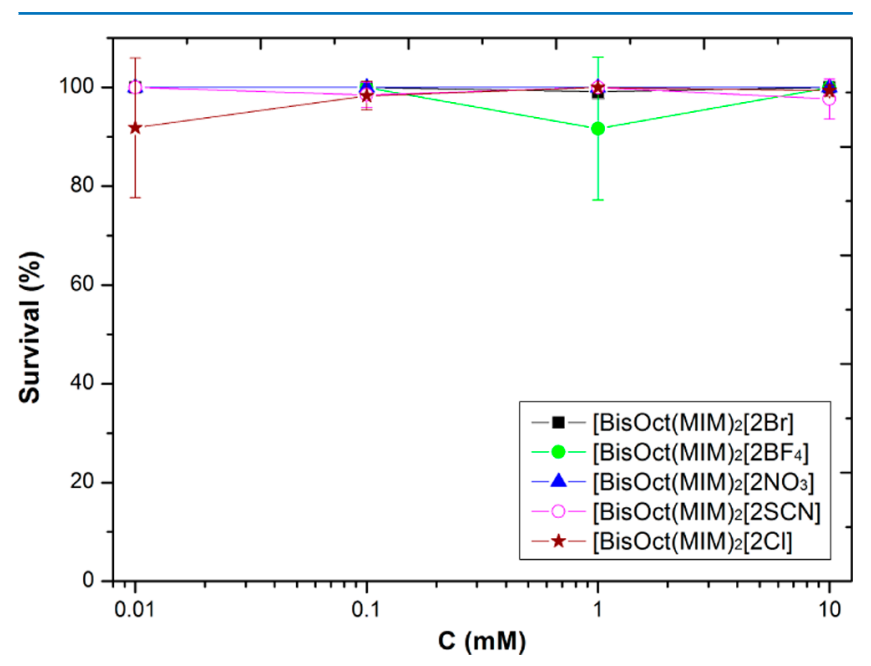

Figure 9. Survival of C. elegans (\%) vs IL concentration.

elegans cannot be evaluated because in all of the ILs tested the survival rate was above $90 \%$. The average lethal dose $\left(\mathrm{LD}_{50}\right)$ for acute exposure $(1 \mathrm{~h})$ of $C$. elegans to the IL series tested was about $>40 \mathrm{mM}$, which indicates low toxic effects. Consequently, it can be deduced that this series is suitable for applications involving animal or human exposure (e.g., lubricants). These previous results will provide the foundation for future more profound investigations to understand the environmental and human health implications of these dicationic ILs.

\section{CONCLUSIONS}

The results show a series of parameters related to dynamics, solubility, toxicity, and thermal stability, in accordance with the properties of the ILs. Establishing all of these properties enables the determination of important applications for these IL 
structures. The degree of solubility, self-diffusion, and relaxation times, in accordance with the anion structure, can determine which ILs act most effectively in chemical reactions, microextractions, and as electrolytes in fuel cells. The following partition constant order was found for the $\left[\mathrm{BisOct}(\mathrm{MIM})_{2}\right]^{2+}$ with different anions: $\left[\mathrm{BF}_{4}\right]^{-}<[\mathrm{SCN}]^{-}<\left[\mathrm{NO}_{3}\right]^{-}<[\mathrm{Br}]^{-}<$ $[\mathrm{Cl}]^{-}$. Furthermore, the nontoxic feature indicates that dicationic ILs can be used for biological and biomedical purposes as lubricants, in controlled drug delivery, and for bioimaging and cell labeling.

The parameters obtained via the $\mathrm{O}-\mathrm{F}-\mathrm{W}$ and Friedman methods furnished relevant information about the degradation of the ILs. The variation in $E_{\mathrm{a}}$ and $\ln A$ values as the fraction of mass conversion $(\alpha)$ increased, indicating a multistep mechanism for ILs with complex anions (formed by multiple atoms connected by covalent bonds). The $E_{\mathrm{a}}$ and $\Delta H^{+}$values found for the IL series were similar in magnitude. Additionally, the $\Delta H^{\ddagger}$ follows the same trend as the $\Delta G^{\ddagger}$. The IL [BisOct(MIM) $\left.)_{2}\right][2 \mathrm{X}]$ with $X=\mathrm{NO}_{3}$ was the most thermally stable structure, followed by $\mathrm{BF}_{4}>\mathrm{Br}>\mathrm{SCN}>\mathrm{NTf}_{2}$, for 10 and $50 \%$ activity loss evaluated. The low stability of $\left[\right.$ BisOct $\left.(\mathrm{MIM})_{2}\right]\left[2 \mathrm{NTf}_{2}\right]$ was attributed to the release of $\mathrm{SO}_{2}$ groups from the anions. The kinetics and thermodynamic parameters of activation furnished important information about the thermal behavior of the structures. These data enabled the estimation of the temperature range for correct and safe application.

\section{EXPERIMENTAL SECTION}

4.1. Materials. 1,8-Dibromooctane, 1,8-dichlorooctane, 1bromooctane, 1-methylimidazole, sodium tetrafluoroborate, silver nitrate, potassium thiocyanate, and bis(trifluoromethane)sulfonimide lithium salt were purchased from Sigma-Aldrich (St. Louis, MO). The acetonitrile and ethyl ether (HPLC grade) were purchased from Tedia (Rio de Janeiro, RJ, Brazil). All of the chemical products were of high-grade purity and used without further purification.

4.2. Synthesis. The ILs were synthesized in accordance with methodologies previously described by Shirota et al. ${ }^{50}$ and developed in our research group. ${ }^{32}$ The structures of all of the products were confirmed by NMR spectroscopy and mass spectroscopy. All of the characterization data of the ILs in this study are shown in the relevant reference. ${ }^{32}$

4.3. Partition Constants. To construct a calibration curve, stock solutions of IL in water $(200 \mathrm{mM})$ were prepared by weighing the IL in a volumetric flask and using an analytical balance with a precision of $\pm 0.001 \mathrm{~g}$ (Marte AL 500, Brazil). The volumetric flask was filled with double-distilled deionized Millipore quality water (Elix-03, Barueri, Brazil; and Milli-Q, Molsheim, France). Stock solutions were analyzed in the UVvis spectrometer and then further diluted to yield other concentrations to be analyzed.

The slow-stirring method was used to determine the partition constant $\left(K_{\mathrm{D}}^{\circ}\right){ }^{22}$ Three milliliter of water containing a known amount of IL (100 mM) was added to a flask and then 1-octanol $(3 \mathrm{~mL})$ was carefully added. The sample was stirred slowly for $24 \mathrm{~h}$ and then the water was separated from 1octanol and analyzed in an optical absorption spectrophotometer (Varian Cary 50 Bio UV/visible Spectrophotometer) at a temperature of $25{ }^{\circ} \mathrm{C}$, which was controlled using a Peltier cell. Both the nomenclature and the symbol used for the partition constant $\left(K_{\mathrm{D}}^{\circ}\right)$ are in accordance with IUPAC recommendations. ${ }^{51}$
4.4. NMR Measurements. The experiments involving diffusion $(D)$ and relaxation times $\left(T_{1}\right.$ and $\left.T_{2}\right)$ were recorded on a Bruker Avance III $\left({ }^{1} \mathrm{H}\right.$ at $\left.600.13 \mathrm{MHz}\right)$ at $298 \mathrm{~K}$. NMR tubes $(5 \mathrm{~mm})$ containing $50 \mathrm{mM}$ of IL solution in water and a sealed capillary tube with TMS diluted in $\mathrm{CDCl}_{3}$ as the external reference (digital resolution of $\pm 0.01 \mathrm{ppm}$ ) were used. Chemical shifts were expressed in $\mathrm{ppm}$. An inversion recovery pulse sequence $\left[180^{\circ}{ }_{x}-\tau-90^{\circ}\right]_{n}$ was used to measure the spin-lattice relaxation time $\left(T_{1}\right)$ at $25{ }^{\circ} \mathrm{C} .{ }^{52}$ Measurements of spin-spin relaxation time $\left(T_{2}\right)$ at $25{ }^{\circ} \mathrm{C}$ were done using the $90^{\circ}{ }_{x}\left[\tau-180^{\circ}{ }_{y} \tau\right]_{n}$ pulse sequence based on the Carr-PurcellMeiboom-Gill (CPMG) method. The self-diffusion coefficient (D) was obtained via the pulsed gradient spin echo (PGSE) method, the pulse sequence STEGP1S was used for samples at $25{ }^{\circ} \mathrm{C}$. These experiments were done to evaluate supramolecular assemblies and intermolecular interactions of ILs in the solution. ${ }^{28,53-56}$

4.5. Thermal Analysis. Thermogravimetric analysis was done on a TGA Q5000 (TA Instruments Inc.). The heating rates were $2,3,5,7$, and $10{ }^{\circ} \mathrm{C} \min ^{-1}$. The $\mathrm{N}_{2}$ flow rate was 25 $\mathrm{mL} \min ^{-1}$ and the temperature range was $298.15-973.15 \mathrm{~K}$. The sample mass was 5-10 mg. The TGA equipment was calibrated by $\mathrm{CaC}_{2} \mathrm{O}_{4} \mathrm{H}_{2} \mathrm{O}(99.9 \%)$.

4.6. Toxicity. 4.6.1. Worm Maintenance. C. elegans Bristol N2 (wild-type) was provided by the Caenorhabditis Genetic Center (CGC, University of Minnesota). All of the strains were grown at $20{ }^{\circ} \mathrm{C}$ on $\mathrm{NGM}$ plates $\left(1.7 \%\right.$ agar, $2.5 \mathrm{mg} \mathrm{mL}^{-1}$ peptone, $25 \mathrm{mM} \mathrm{NaCl}$, $50 \mathrm{mM} \mathrm{KH}_{2} \mathrm{PO}_{4} \mathrm{pH} 6.0,5 \mu \mathrm{g} \mathrm{mL}^{-1}$ cholesterol, $1 \mathrm{mM} \mathrm{CaCl}_{2}, 1 \mathrm{mM} \mathrm{MgSO}_{4}$ ) with fresh Escherichia coli OP50 as the food source. For each experiment, synchronized populations were obtained by the disruption of gravid adults. Worms were grown to the L1 larval stage on NGM/OP50-seeded plates.

4.6.2. C. elegans Experimental Treatments. L1 larval-stage worms were exposed to ILs for $1 \mathrm{~h}$ at different concentrations. The worms were transferred to $1.5 \mathrm{~mL}$ conical tubes containing M9 buffer, together with each respective IL. The worms were kept under constant shaking for oxygenation. After $1 \mathrm{~h}$, the worms were washed three times with M9 and transferred to NGM plates seeded with OP50. After $24 \mathrm{~h}$, we performed the survival assay.

\section{ASSOCIATED CONTENT}

\section{Supporting Information}

The Supporting Information is available free of charge on the ACS Publications website at DOI: 10.1021/acsomega.7b01873.

Spectra ( ${ }^{1} \mathrm{H}$ NMR and UV-vis) and thermal data of all ILs (PDF)

\section{AUTHOR INFORMATION}

\section{Corresponding Author}

*E-mail: clarissa.frizzo@gmail.com.

ORCID $\odot$

Clarissa P. Frizzo: 0000-0002-1175-7880

Caroline R. Bender: 0000-0002-5791-4730

Paulo R. S. Salbego: 0000-0001-7774-6327

\section{Notes}

The authors declare no competing financial interest. 


\section{ACKNOWLEDGMENTS}

The authors are grateful for the financial support from the Coordination for Improvement of Higher Education Personnel (CAPES/PROEX). The fellowships from CNPq (M.A.P.M., C.P.F., C.R.B., P.R.S.S., and M.A.V.) and CAPES are also acknowledged.

\section{REFERENCES}

(1) Frizzo, C. P.; Gindri, I. M.; Bender, C. R.; Tier, A. Z.; Villetti, M. A.; Rodrigues, D. C.; Machado, G.; Martins, M. A. P. P. Effect on Aggregation Behavior of Long-Chain Spacers of Dicationic Imidazolium-Based Ionic Liquids in Aqueous Solution. Colloids Surf., A 2015, 468, 285-294.

(2) Brown, L.; Earle, M. J.; Gîlea, M. A.; Plechkova, N. V.; Seddon, K. R. Ionic Liquid-Liquid Chromatography: A New General Purpose Separation Methodology. Top. Curr. Chem. 2017, 375, 1-41.

(3) Wang, K.; Adidharma, H.; Radosz, M.; Wan, P.; Xu, X.; Russell, C. K.; Tian, H.; Fan, M.; Yu, J. Recovery of Rare Earth Elements with Ionic Liquids. Green Chem. 2017, 19, 4469-4493.

(4) Tang, S.; Baker, G. A.; Zhao, H. Ether- and AlcoholFunctionalized Task-Specific Ionic Liquids: Attractive Properties and Applications. Chem. Soc. Rev. 2012, 41, 4030-4066.

(5) Amarasekara, A. S. Acidic Ionic Liquids. Chem. Rev. 2016, 116, 6133-6183.

(6) Itoh, T. Ionic Liquids as Tool to Improve Enzymatic Organic Synthesis. Chem. Rev. 2017, 117, 10567-10607.

(7) Zeng, S.; Zhang, X.; Bai, L.; Zhang, X.; Wang, H.; Wang, J.; Bao, D.; Li, M.; Liu, X.; Zhang, S. Ionic-Liquid-Based CO2 Capture Systems: Structure, Interaction and Process. Chem. Rev. 2017, 117, 9625-9673.

(8) Dai, C.; Zhang, J.; Huang, C.; Lei, Z. Ionic Liquids in Selective Oxidation: Catalysts and Solvents. Chem. Rev. 2017, 117, 6929-6983.

(9) Ventura, S. P. M.; e Silva, F. A.; Quental, M. V.; Mondal, D.; Freire, M. G.; Coutinho, J. A. P. Ionic-Liquid-Mediated Extraction and Separation Processes for Bioactive Compounds: Past, Present, and Future Trends. Chem. Rev. 2017, 117, 6984-7052.

(10) Hallett, J. P.; Welton, T. Room-Temperature Ionic Liquids: Solvents for Synthesis and Catalysis. 2. Chem. Rev. 2011, 111, 35083576.

(11) Stassen, H. K.; Ludwig, R.; Wulf, A.; Dupont, J. Imidazolium Salt Ion Pairs in Solution. Chem. - Eur. J. 2015, 21, 8324-8335.

(12) Kaintz, A.; Baker, G.; Benesi, A.; Maroncelli, M. Solute Diffusion in Ionic Liquids, NMR Measurements and Comparisons to Conventional Solvents. J. Phys. Chem. B 2013, 117, 11697-11708.

(13) Salman, S. M.; Narayanaperumal, S.; Schwab, R. S.; Bender, C. R.; Rodrigues, O. E. D.; Dornelles, L. CuO Nano Particles and [bmim]BF4: An Application towards the Synthesis of Chiral $\beta$-Seleno Amino Derivatives via Ring Opening Reaction of Aziridines with Diorganyl Diselenides. RSC Adv. 2012, 2, 8478-8482.

(14) Baltazar, Q. Q.; Chandawalla, J.; Sawyer, K.; Anderson, J. L. Interfacial and Micellar Properties of Imidazolium-Based Monocationic and Dicationic Ionic Liquids. Colloids Surf., A 2007, 302, $150-156$.

(15) Ding, Z.; Hao, A. Synthesis and Surface Properties of Novel Cationic Gemini Surfactants. J. Dispersion Sci. Technol. 2010, 31, 338342.

(16) Gindri, I. M.; Frizzo, C. P.; Bender, C. R.; Tier, A. Z.; Martins, M. A. P.; Villetti, M. A.; Machado, G.; Rodriguez, L. C.; Rodrigues, D. C. Preparation of $\mathrm{TiO} 2$ Nanoparticles Coated with Ionic Liquids: A Supramolecular Approach. ACS Appl. Mater. Interfaces 2014, 6, 11536-11543.

(17) Maton, C.; De Vos, N.; Stevens, C. V. Ionic Liquid Thermal Stabilities: Decomposition Mechanisms and Analysis Tools. Chem. Soc. Rev. 2013, 42, 5963-5977.

(18) Domańska, U.; Królikowski, M.; Pobudkowska, A.; Bocheńska, P. Solubility of Ionic Liquids in Water and Octan-1-Ol and Octan-1$\mathrm{Ol} /$ water, or 2-Phenylethanol/water Partition Coefficients. J. Chem. Thermodyn. 2012, 55, 225-233.
(19) Oliveira, M. V. S.; Vidal, B. T.; Melo, C. M.; de Miranda, R. d. C. M.; Soares, C. M. F.; Coutinho, J. A. P.; Ventura, S. P. M.; Mattedi, S.; Lima, Á. S. (Eco)toxicity and Biodegradability of Protic Ionic Liquids. Chemosphere 2016, 147, 460-466.

(20) Pham, T. P. T.; Cho, C.-W.; Yun, Y.-S. Environmental Fate and Toxicity of Ionic Liquids: A Review. Water Res. 2010, 44, 352-372.

(21) Weingärtner, H. NMR Studies of Ionic Liquids: Structure and Dynamics. Curr. Opin. Colloid Interface Sci. 2013, 18, 183-189.

(22) Ropel, L.; Belvèze, L. S.; Aki, S. N. V. K.; Stadtherr, M. A.; Brennecke, J. F. Octanol-water Partition Coefficients of ImidazoliumBased Ionic Liquids. Green Chem. 2005, 7, 83-90.

(23) Lee, S. H.; Lee, S. B. Octanol/water Partition Coefficients of Ionic Liquids. J. Chem. Technol. Biotechnol. 2009, 84, 202-207.

(24) Jain, P.; Kumar, A. Concentration-Dependent Apparent Partition Coefficients of Ionic Liquids Possessing Ethyl- and BiSulphate Anions. Phys. Chem. Chem. Phys. 2016, 18, 1105-1113.

(25) Marcus, Y. Thermodynamics of Solvation of Ions. J. Chem. Soc. Faraday Trans. 1991, 87, 2995-2999.

(26) Chapeaux, A.; Simoni, L. D.; Stadtherr, M. A.; Brennecke, J. F. Liquid Phase Behavior of Ionic Liquids with Water and 1-Octanol and Modeling of 1-Octanol/water Partition Coefficients. J. Chem. Eng. Data 2007, 52, 2462-2467.

(27) Chung, S. H.; Lopato, R.; Greenbaum, S. G.; Shirota, H.; Castner, E. W.; Wishart, J. F. Nuclear Magnetic Resonance Study of the Dynamics of Imidazolium Ionic Liquids with $-\mathrm{CH} 2 \mathrm{Si}(\mathrm{CH} 3) 3$ vs $-\mathrm{CH}_{2} \mathrm{C}\left(\mathrm{CH}_{3}\right)_{3}$ Substituents. J. Phys. Chem. B 2007, 111, 4885-4893.

(28) Burrell, G. L.; Burgar, I. M.; Gong, Q.; Dunlop, N. F.; Separovic, F. NMR Relaxation and Self-Diffusion Study at High and Low Magnetic Fields of Ionic Association in Protic Ionic Liquids. J. Phys. Chem. B 2010, 114, 11436-11443.

(29) Claridge, T. D. W. High-Resolution NMR Techniques in Organic Chemistry, 2nd ed.; Bäckvall, J.-E., Baldwin, J. E., Williams, R. M., Eds.; Elsevier: Amsterdam, 2009.

(30) Hayamizu, K.; Tsuzuki, S.; Seki, S.; Umebayashi, Y. Nuclear Magnetic Resonance Studies on the Rotational and Translational Motions of Ionic Liquids Composed of 1-Ethyl-3-Methylimidazolium Cation and Bis(trifluoromethanesulfonyl)amide and Bis(fluorosulfonyl)amide Anions and Their Binary Systems Including Li. J. Chem. Phys. 2011, 135, No. 084505.

(31) Frizzo, C. P.; Bender, C. R.; de Mello Gindri, I.; Villetti, M. A.; Machado, G.; Bianchi, O.; Martins, M. A. P. Elucidating Anion Effect on Nanostructural Organization of Dicationic Imidazolium-Based Ionic Liquids. J. Phys. Chem. C 2016, 120, 14402-14409.

(32) Frizzo, C. P.; Bender, C. R.; Gindri, I. M.; Salbego, P. R. S.; Villetti, M. A.; Martins, M. A. P. Anion Effect on the Aggregation Behavior of the Long-Chain Spacers Dicationic Imidazolium-Based Ionic Liquids. Colloid Polym. Sci. 2015, 293, 2901-2910.

(33) Frizzo, C. P.; Villetti, M. A; Tier, A. Z.; Gindri, I. M.; Buriol, L.; Rosa, F. A.; Claramunt, R. M.; Sanz, D.; Martins, M. A. P. Structural and Thermodynamic Properties of New pyrazolo[3,4-D]pyridazinones. Thermochim. Acta 2013, 574, 63-72.

(34) Souza, D.; Castillo, T. E.; Rodríguez, R. J. S. Impacto Do CoMonômero Hidroxivalerato $\mathrm{Na}$ Cinética de Degradação Térmica Dos poli(3-Hidroxialcanoatos). Matéria 2009, 14, 946-956.

(35) Arellano, I. H. J.; Guarino, J. G.; Paredes, F. U.; Arco, S. D. Thermal Stability and Moisture Uptake of 1-Alkyl-3-Methylimidazolium Bromide. J. Therm. Anal. Calorim. 2011, 103, 725-730.

(36) Kroon, M. C.; Buijs, W.; Peters, C. J.; Witkamp, G. J. Quantum Chemical Aided Prediction of the Thermal Decomposition Mechanisms and Temperatures of Ionic Liquids. Thermochim. Acta 2007, $465,40-47$.

(37) Shamsipur, M.; Pourmortazavi, S. M.; Beigi, A. A. M.; Heydari, R.; Khatibi, M. Thermal Stability and Decomposition Kinetic Studies of Acyclovir and Zidovudine Drug Compounds. AAPS PharmSciTech 2013, 14, 287-293.

(38) Heym, F.; Etzold, B. J. M.; Kern, C.; Jess, A. Analysis of Evaporation and Thermal Decomposition of Ionic Liquids by Thermogravimetrical Analysis at Ambient Pressure and High Vacuum. Green Chem. 2011, 13, 1453-1466. 
(39) Rebelo, L. P. N.; Lopes, J. N. C.; Esperança, J. M. S. S.; Filipe, E. On the Critical Temperature, Normal Boiling Point, and Vapor Pressure of Ionic Liquids. J. Phys. Chem. B 2005, 109, 6040-6043.

(40) Egorova, K. S.; Ananikov, V. P. Toxicity of Ionic Liquids: Eco(cyto)activity as Complicated, but Unavoidable Parameter for Task-Specific Optimization. ChemSusChem 2014, 7, 336-360.

(41) McLaughlin, M.; Earle, M. J.; Gîlea, M. A.; Gilmore, B. F.; Gorman, S. P.; Seddon, K. R. Cytotoxicity of 1-Alkylquinolinium Bromide Ionic Liquids in Murine Fibroblast NIH 3T3 Cells. Green Chem. 2011, 13, 2794-2800.

(42) Stolte, S.; Arning, J.; Bottin-Weber, U.; Matzke, M.; Stock, F.; Thiele, K.; Uerdingen, M.; Welz-Biermann, U.; Jastorff, B.; Ranke, J. Anion Effects on the Cytotoxicity of Ionic Liquids. Green Chem. 2006, $8,621-629$.

(43) Steudte, S.; Bemowsky, S.; Mahrova, M.; Bottin-Weber, U.; Tojo-Suarez, E.; Stepnowski, P.; Stolte, S. Toxicity and Biodegradability of Dicationic Ionic Liquids. RSC Adv. 2014, 4, 5198-5205.

(44) Gindri, I. M.; Siddiqui, D. A.; Bhardwaj, P.; Rodriguez, L. C.; Palmer, K. L.; Frizzo, C. P.; Martins, M. A. P.; Rodrigues, D. C. Dicationic Imidazolium-Based Ionic Liquids: A New Strategy for NonToxic and Antimicrobial Materials. RSC Adv. 2014, 4, 62594-62602.

(45) Zhao, D.; Liao, Y.; Zhang, Z. D. Toxicity of Ionic Liquids. Clean: Soil, Air, Water 2007, 35, 42-48.

(46) Ranke, J.; Stolte, S.; Störmann, R.; Arning, J.; Jastorff, B. Design of Sustainable Chemical Products-the Example of Ionic Liquids. Chem. Rev. 2007, 107, 2183-2206.

(47) Höss, S.; Weltje, L. Endocrine Disruption in Nematodes: Effects and Mechanisms. Ecotoxicology 2007, 16, 15-28.

(48) Leung, M. C. K.; Williams, P. L.; Benedetto, A.; Au, C.; Helmcke, K. J.; Aschner, M.; Meyer, J. N. Caenorhabditis Elegans: An Emerging Model in Biomedical and Environmental Toxicology. Toxicol. Sci. 2008, 106, 5-28.

(49) Wu, X.; Tong, Z.-H.; Li, L.-L.; Yu, H.-Q. Toxic Effects of Imidazolium-Based Ionic Liquids on Caenorhabditis Elegans: The Role of Reactive Oxygen Species. Chemosphere 2013, 93, 2399-2404.

(50) Shirota, H.; Mandai, T.; Fukazawa, H.; Kato, T. Comparison between Dicationic and Monocationic Ionic Liquids: Liquid Density, Thermal Properties, Surface Tension, and Shear Viscosity. J. Chem. Eng. Data 2011, 56, 2453-2459.

(51) IUPAC Gold Book. https://goldbook.iupac.org/html/P/ P04438.html (accessed Nov 13, 2017).

(52) Vold, R. L.; Waugh, J. S.; Klein, M. P.; Phelps, D. E. Measurement of Spin Relaxation in Complex Systems. J. Chem. Phys. 1968, 48, 3831-3832.

(53) Desando, M. A.; Lahajnar, G.; Sepe, A. Proton Magnetic Relaxation and the Aggregation of N-Octylammonium N-Octadecanoate Surfactant in Deuterochloroform Solution. J. Colloid Interface Sci. 2010, 345, 338-345.

(54) Mota, A. A. R.; Gatto, C. C.; Machado, G.; De Oliveira, H. C. B.; Fasciotti, M.; Bianchi, O.; Eberlin, M. N.; Neto, B. A. D. Structural Organization and Supramolecular Interactions of the Task-Specific Ionic Liquid 1-Methyl-3-Carboxymethylimidazolium Chloride: Solid, Solution, and Gas Phase Structures. J. Phys. Chem. C 2014, 118, 17878-17889.

(55) Singh, T.; Kumar, A. Aggregation Behavior of Ionic Liquids in Aqueous Solutions: Effect of Alkyl Chain Length, Cations, and Anions. J. Phys. Chem. B 2007, 111, 7843-7851.

(56) Blanchard, J. W.; Beli, J.; Alam, T. M.; Yarger, J. L.; Holland, G. P. NMR Determination of the Diffusion Mechanisms in Triethylamine-Based Protic Ionic Liquids. J. Phys. Chem. Lett. 2011, 2, 10771081. 